\title{
STIMULATING INNOVATIVE BEHAVIOUR IN NATIONAL SYSTEMS OF INNOVATION: THEORETICAL, METHODOLOGICAL AND POLICY PITFALLS AND CHALLENGES
}

\author{
L.A.G. Oerlemans ${ }^{1}$ and M.W. Pretorius ${ }^{2}$ \\ ${ }^{1}$ Department of Organization Studies \\ Tilburg University, The Netherlands and \\ Department of Engineering and Technology Management \\ University of Pretoria, South Africa \\ l.a.g.oerlemans@uvt.nl \\ ${ }^{2}$ Department of Engineering and Technology Management \\ University of Pretoria, South Africa \\ tinus.pretorius@eng.up.ac.za
}

\begin{abstract}
South Africa was one of the first countries in the world that adopted a Systems of Innovation approach as its policy framework. By adopting this approach, one also inherits the problems, pitfalls, and challenges of a framework. This paper evaluates the Systems of Innovation approach from a theoretical, methodological, and policy perspective. Equipped with this knowledge, researchers can guide their research efforts, whereas policy makers can design more appropriate policy measures fitting and stimulating the functioning and effectiveness of a System of Innovation.
\end{abstract}

\section{OPSOMMING}

Suid-Afrika was een van die eerste lande wat 'n Stelsel van Innovasie as grondslag vir ' $n$ beleidsraamwerk aanvaar het. Die inherente probleme, slaggate en uitdagings van so ' $\mathrm{n}$ raamwerk is egter belangrike faktore om in ag te neem. Hierdie artikel evalueer die Stelsel van Innovasie-benadering vanuit ' $n$ teoretiese, metodologiese en beleidsperspektief. Die bevindings kan as nuttige riglyne vir navorsingsbeplanning dien, terwyl beleidmakers meer toepaslike instrumente vir die stimulering van ' $n$ funksionele en effektiewe Stelsel van Innovasie kan ontwerp. 


\section{INTRODUCTION}

Innovation, defined as the introduction into the market (economic or social) of new or improved processes, products and services, is globally accepted as the engine of economic growth and has become an important factor in the survival and prosperity of modern economic and social systems. Throughout the years, national governments implemented a variety of policy instruments to stimulate innovation. These instruments ranged from regulations to protect (intellectual) property rights, patents, and brand names to measures for promoting (innovative) entrepreneurship, providing venture capital, the development of economic and social infrastructure, subsidizing Research and Development and the transfer of knowledge, and diminishing trade barriers. Most of these policy measures are developed with neo-classical economic theory as a basis and tend to have a supply-side orientation. However, many studies in the fields of technology and innovation management and the economics of innovation showed that innovation is a far more complex process in which a variety of actors (not only firms) interact to produce innovations.

The System of Innovation approach acknowledged these interactive and complex features of the innovation process and developed as an independent scientific school of thought fuelled amongst others by the work of Lundvall. When the idea of an innovation system approach was first discussed in the middle 1980s nobody expected it to become as widely disseminated as it is today. International organisations (OECD, EC, UNCTAD) as well as governments (South Africa, Finland and more recently Sweden) have adopted the concept as a part of their analytical and policy perspective.

As a matter of fact, South Africa was the first country in the world to adopt this framework as its national policy [34]. This policy framework was further developed in South Africa's National Research and Development Strategy that was published in 2002. The South African national R\&D strategy rests on three pillars. The first pillar is innovation, which involves the establishment and funding of a number of technology missions that are regarded as critical to promote economic and social development. These platforms are biotechnology, information technology, technology for manufacturing, technology to leverage knowledge and technology from natural resources sectors, and technology for poverty reduction. It is added that this portfolio of missions needs to be managed in a coherent and integrated way, which initially will be the responsibility of the Department of Science and Technology. The second pillar, and connected to the first one, is human resource development. The approach to this pillar is rooted in the need, on the one hand, to radically increase the number of people (especially women) from previously disadvantaged communities entering the scientific community and remaining there, and on the other hand, a strategy to maximise the pursuit of excellence in global terms. The National Research Foundation is seen as a key institution for this pillar. The third pillar aims at creating an effective government Science and Technology system, which implies attributing clear roles for governmental departments and ensuring that international best practice with respect to state funding of science and technology, is accomplished. 
Despite its popularity amongst scientists and policy makers, the System of Innovation approach is problematic but at the same time challenging. These problems and challenges will be discussed from a theoretical, a methodological, and a policy point of view. Therefore, the research question of this paper reads: What are the theoretical, methodological, and policy problems and challenges of the System of Innovation approach? The aim of the paper is to provide insight into the present state of affairs in System of Innovation research. Equipped with this knowledge, researchers can guide their research efforts, whereas policy makers can design more appropriate policy measure to fit and stimulate the functioning of the System of Innovation.

The remainder of this paper is structured as follows: In Section 2, the concept of Systems of Innovation is defined. Next, the characteristics and theoretical antecedents of System of Innovation approaches are discussed in two subsections. Section 3 diagnoses the present state of affairs in System of Innovation approaches by discussing theoretical, methodological, and policy issues. Section 4 provides directions of future research. The final section of the paper summarises the most important conclusion. Moreover, we will reflect upon the main features of the South African science and technology policy in the light of the findings of this paper.

\section{SYSTEM OF INNOVATION APPROACHES}

\subsection{The concept of Systems of Innovation}

Innovation systems can be defined as [24]: That set of distinct institutions which jointly and individually contribute to the development and diffusion of new technologies and which provide the framework within which governments form and implement policies to influence the innovation process. As such it is a system of interconnected institutions to create, store and transfer the knowledge, skills and artefacts that define new technologies. The graphic representation below illustrates the composition of such a system of innovation.

Figure 1 shows that a National System of Innovation consists of several subsystems that interact with each other in the form of flows of resources of different natures. To give a few examples: There is interactive flow of knowledge, skills, funds, and artefacts (solid arrows) between the Education and Research System and Industrial Systems part of the model. Here, one could think of a flow of graduates 'produced' by the one system and employed by the other, or collaborative effects in which industry and universities interactively develop new knowledge. Besides flows of knowledge, skills, funds, and artefacts, flows in systems of innovation can be of a regulatory nature (dotted arrows). For instance, through regulatory measures the political system can stimulate an infrastructure that supports the development of standards and norms which are conducive to innovation. Moreover, the Political System could put in to place conditions that favor industry-university-collaboration.

The basic question to be asked about the effectiveness of an Innovation System is: What are the factors that determine the degree to which new technologies succeed in 
a competition for resources and thus become a foundation for successful future technological developments? One can easily discern a macro and micro side to this question. To what extent do (inter)national science, technology and innovation policies guide and influence these developments? To what extent do innovator firms foster or inhibit these technological developments? If technologically superior

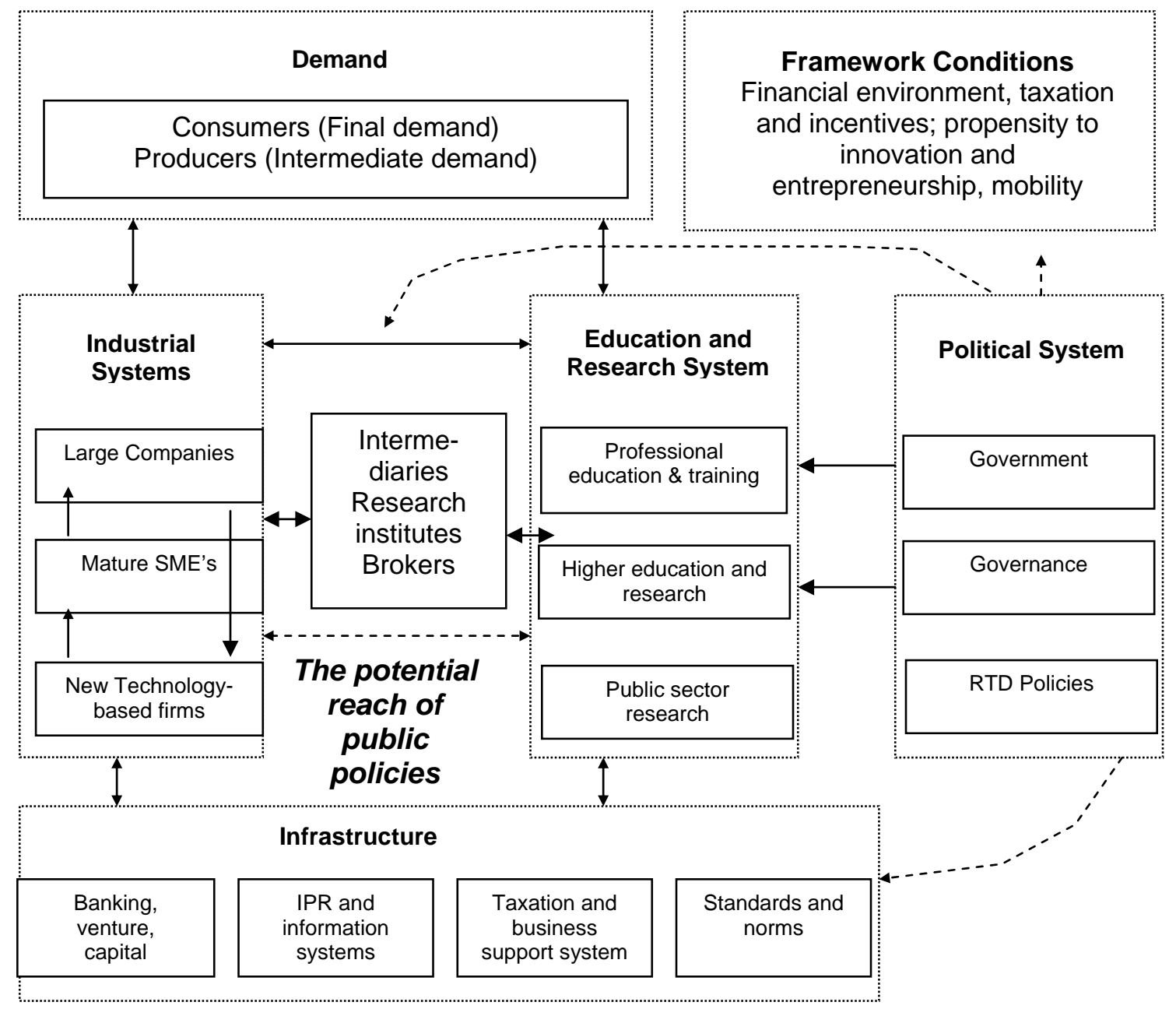

Figure 1: The composition of a system of innovation

innovations were always to dominate technically inferior ones, then the answer to the aforementioned question would simply depend upon the technical attributes that make a particular innovation superior. But there is ample evidence that the best technologies for example on the basis of price-to-performance ratios are not necessarily the most successful ones, and this means that technical specifications alone may not be successful ones to gauge the likelihood of technological success at a micro and or macro level [28]. The fundamental theoretical starting point for examining these questions is that technologies are dual phenomena [1]. As large technical systems, as embodied artefact, or as disembodied procedure (test technology), technologies consist of an assembly of material, components, and interfaces, which all have a defined function. Simultaneously these elements cannot be thought of without their producers and users, and their behaviors pursuing their production and diffusion. Hence a technology comprises a 'network' of human and 
non-human elements, which means that technologies also represent technological communities (of competitors, producers, users, educators, researchers and policy makers). The process of innovation leading to technical change can then be thought of as interaction of behaviors of actors producing or using technologies, which ultimately result in redesign or new design of technical systems.

\subsection{Characteristics of system of innovation approaches}

The recent emergence of Systems of Innovation approaches can be seen as a logical extension of systems-oriented theory and research in the economics of innovation. System of Innovation theorising includes non-linearity and interdependence. Seven characteristics of System of Innovation approaches have been identified [7]:

- Innovation and learning processes are placed at the centre of focus. Technological innovation is viewed as a matter of producing new knowledge or combining existing knowledge elements in new ways. Therefore, it is a learning process at different levels (individual, organization, network, (sub)system) in the broadest sense.

- The adoption of a holistic and interdisciplinary perspective. It is interdisciplinary in the sense that they not only include economic but also organisational, social and technical perspectives.

- The employment of historical perspectives. Since processes of innovation develop over time and include the influence of many factors and feedback loops, they are often studied in terms of the (co-)evolution of knowledge, innovations, organisations and institutions.

- The approaches tend to stress differences between systems, rather than the optimality of systems. The main focus is on differences between systems of innovation, rather than something to be abstracted away from. This implies conducting comparative research on existing systems, rather than between real systems and an ideal or optimal system.

- An emphasis on interdependence and non-linearity. This emphasis is based on the understanding that organisations almost never innovate in isolation but interact more or less closely with other organisations through complex relations often characterised by reciprocity and feedback mechanisms. The interaction occurs in the context of institutions such as laws, rules, regulations, norms and cultural habits. Therefore, innovations are not only determined by the elements of the systems, but also by the relations and interactions between them.

- The approaches encompass product and process technologies, as well as organisational innovations. This is based on the understanding that developing a differentiated concept of innovation that is not only restricted to process innovations of a technical nature, is needed to comprehend the complex relations between growth, employment, and innovation. 
- The approaches emphasise the central role of institutions. The importance of institutions is stressed since it enables the understanding of the social patterning of innovative behaviour and the role played by norms, rules, laws, and by organisations.

\subsection{Antecedents of System of Innovation approaches}

Selected economic theories. Although scholars working within the National Innovation System approach are anything but proponents of neo-classical economic theory, the approach is in a certain way heavily influenced by neo-classical economic theory, since it takes neo-classical theory as a negative benchmark. This can be illustrated in two ways: the way technological knowledge is conceptualised, and the relation between coordination mechanisms (mechanisms to organize transactions) and innovation.

According to Smith [33], neo-classical (production) theory rests on an implied and implicit form of technological knowledge with very specific characteristics. He argues that in a neo-classical world, technological knowledge must have the following features for the production theory to hold:

- It is generic: An item of knowledge can be applied widely among firms and even among industries.

- It is codified: Transmitability implies that knowledge is written or otherwise recorded in fairly usable form.

- It is costlessly accessible: Transmission costs are negligible, or firms are not faced with differential cost barriers to obtain knowledge and bring it into production.

- It is context independent: Firms have equal competences in transforming knowledge into production capabilities.

As a result of the unrealistic nature of these features, modern innovation theories, like the NIS approach, tend to emphasise quite different aspects of technological knowledge, and hence provide a different view on the issue of technological knowledge. Technological knowledge is conceptualised as a knowledge base with which organizations can strive for competitive advantage. Such knowledge bases are as follows [33: 80-81]:

- Differentiated and multi-layered, consisting of articulated forms of different knowledge.

- Highly specific, organised around a relatively limited set of functions which firms understand well.

- Cumulative since the development of these knowledge bases are costly search processes, through processes of learning and adaptation, in which firms build up experience with specific technologies.

- Internally systemic, being part of an overall production system which has many components. Technological innovation involves a wide array of activities, which must be organised and managed by the innovating firm. 
- Interactive and externally systemic: technological innovation usually involves, either implicitly or explicitly, structured interaction between institutions, involving processes of mutual learning and knowledge and information exchange.

As to the relationship between coordination mechanisms and innovation, the discussion in neo-classical economic theory is strongly informed by the well-known papers by Arrow [2] and Demsetz [6]. Arrow's theoretical model indicates that the incentive to innovate is greater in a competitive market situation as compared to a monopoly one, provided that patent law protects the innovation that ensures that the innovator can recover its R\&D investments. Demsetz's analysis, however, predicted that under certain conditions the incentive to innovate would be equal in both market structures and in other situations (e.g. when entry barriers can be put in place and maintained by the monopolist) the monopoly market structure would be more conducive for innovation. However, empirical evidence on this relationship is inconclusive, some studies support the Arrow model [14], whereas others find evidence confirming the Demsetz model [17].

In a search for a new theory of the firm, some scholars found the classical dichotomy "market versus hierarchy" (= monopoly) rather artificial and not in line with everyday practices of organizations. Especially the growth of all kinds of interorganizational forms like joint ventures, strategic alliances and technology networks could not be explained by traditional neo-classical economic theory. Especially transaction cost economic theory as developed by Williamson [35] provided a new (neo-classical) answer to this issue. Williamson showed that under certain conditions (bounded rationality and opportunism) and taking specific characteristics of transactions into account (frequency, uncertainty, asset specificity) the existence of other coordination mechanisms than market and monopoly to organize transactions are theoretically possibly (e.g. trilateral and bilateral contracting (= networks)). Williamson's theoretical work set the stage for the development of the notion of the "organised markets", which is an important ingredient in the NIS approach, and the further development of economic network theory (see below).

Interactive learning theories. Lundvall's work [21] is an example of the broad approach which attempts to explicitly relate the national context to interactive learning - the process in which agents communicate and even cooperate in the creation and utilisation of new economically useful knowledge [22:226] - theories of innovation. This framework stresses processes of learning and user-producer interaction. Because the innovation process is conceptualised as an interactive one, the notion of interaction paves the way for a systemic approach.

Evolutionary theories. As an antipode against the view that technical change is purely the result of profit maximising behaviour, Nelson and Winter [25] proposed to view technical change as an evolutionary process. This view contains the following elements:

- Starting point is the existence and reproduction of entities. In innovation studies, these entities are certain set-ups of technologies and organisational forms. 
- There are mechanisms that introduce novelties in the systems, i.e., generate diversity or variety. On the one hand, these mechanisms encompass randomness; while on the other purpose-oriented research is included too. These mechanisms produce mutations, i.e., innovations.

- There are mechanisms that select among the entities in the systems. As a result of selection, the relative importance of some entities increases, while that of others diminishes. The selection process reduces variety and the mechanisms at work may be market or institutional selection. These mechanisms act as a filtering system and produce a new set-up of technologies or organisational forms.

Theories on interdependencies and interaction. Besides interactive learning and evolutionary theories, perspectives on innovation in which interdependencies and interaction between users, producers, and other actors can be considered to be of importance for the development of the System of Innovation approaches. Firstly, the introduction of the chain-linked model of innovation [19] has to be mentioned. Apart from pointing to the non-linearity nature of technological development, the model emphasises the role of the demand side in innovation processes and it stresses that innovation is not only a research-driven process. Secondly, the notion of interconnectedness was complemented by Von Hippel's [16] theory of variation in sources of innovation. This theory challenged long-standing assumptions that product manufactures are the only sources of product innovations and substituted them with a model of a distributed innovation process in which (product) innovations could originate from any one (or combinations) of at least three distinct sources, i.e., suppliers, producers, and users, and simultaneously introducing the concept of the 'lead user'. A third precursor is the Aalborg school's research on the learning dimension of user-producer interaction in product innovation. The main point of departure in this research was a critique of orthodox views of innovation as a process of 'learning by doing' taking place within firms situated in perfectly competitive markets. The Aalborg research pointed to the existence of organised markets, which meet the needs for qualitative information about new use-values as inputs and about the needs of users [20]. Interactive learning theory's strong emphasis on institutional analysis led to the identification of a broad realm of economic relationships and innovative activities that belonged to 'neither market nor hierarchy' (see above: Transaction Cost Theory). This, in turn, allowed for another important influence on System of Innovation, namely emerging theory and research on networks of innovators. There is now a vast body of literature on networks as a specific form of economic organisation and much of this work has dealt with themes such as learning and innovation [5]. In particular, Håkansson's work on industrial networks [15] has been cited as an important influence on System of Innovation approaches [3, 13]. In this literature, it is argues that the functions of networks for innovation are threefold. Networks function as a coordination device facilitating learning, they help to exploit and provide access to technological complementary assets, and serve as a platform for technological combination. 


\section{TOWARDS A RESEARCH AGENDA}

\subsection{Systems of Innovation Management: theoretical issues}

As Edquist [7, 8] noted, from a theoretical perspective the System of Innovation approaches are still associated with (conceptual) diffuseness. This diffuseness concerns the use of concepts in different and inconsistent ways, the vague way the functional boundaries of the systems are defined, and the way relations between variables are loosely described. Therefore, further development will evolve progressing from the present state of 'conceptual pluralism' to a state in which core concepts and their precise contents are clearer, reducing pluralism and ambiguity in the process. In an evaluation of System of Innovation approaches, Meeus and Oerlemans [23] argue that the present state of theorizing can be explained by the variety of disciplines involved and the high policy orientation of the research. On the one hand, the issue of innovation systems turns out to be a new field of research where novel combinations of economic growth theory, international trade theory, evolutionary theory, industrial organisation theory, organisation sociology, regional sciences, and institutional approaches emerge and are applied. On the other, many of the researchers in the field are strongly policy oriented, and are in general not much interested in conceptual clarification and theoretical explanation. In tandem, these features cause a low level of theoretical development and the ad hoc character of much System of Innovation research. In their view, there are two important theoretical gaps in the System of Innovation literature. Firstly, it puts institutions at the centre of the analysis without unpacking institutional arguments. That is, at a theoretical level, System of Innovation literature does not make clear how normative, regulatory, and cognitive institutions influence innovative behaviour. Secondly, it disregards the tension between the systems approach and the role of agency and firm behaviour. The systems approach often suggests natural boundaries as well as a certain level of coherence between subsystems. This indicates one of the problems with this approach, namely the risk to get bound up in a functionalist and deterministic universe where it is impossible to locate sources of change. Inevitably, actors within a system are conceived of as puppets on institutional strings.

\subsection{Systems of Innovation Management: methodological issues}

Several scholars point at methodological weaknesses of System of Innovation approaches. A first issue concerns the question of the appropriate level of analysis. Edquist [8], for example, argues that a great deal of writing within the Systems of Innovation tradition is focussed on technological change at a macro level and not on innovation in a broader sense at lower levels of aggregation. Moreover, among studies of technological innovations the focus was often implicitly on (effects of) technological process innovations. In his view, the study of the determinants of innovations, activities in and functions of Systems of Innovations is the area of basic research in the field of innovation studies. Since the array of determinants of innovations and the relations between them can be expected to vary considerably, it is insufficient, states Edquist, to focus on the macro level only. 
Also Carlsson et al. [4] discussed the level of analysis issue. In their methodological review of system of innovation studies, they found that the approach was fruitfully applied to at least four levels of analysis. Firstly, it was applied to a technology in the sense of a knowledge field. An example of a technology/knowledge field may be digital signal processing, which may be used to study the diffusion of this technology into different applications. A second application is to a product or an artefact. For example, an industrial robot consists of a number of technologies (drive, sensor and control technologies) and this artefact can be studied for its links with its customer groups and how these influence the technical features of the artefact. Thirdly, to a set of related products and artefacts aimed at satisfying a particular function in economic or social life. Here the focus is on a set of products (complementary or substitute), which are related by having a common market, for example the health care market, operate under the same institutional arrangement, and therefore, share a common selection environment. A fourth and final field of application is to a set of related firms (vertically or horizontally linked) operating in different markets and serving different functions. This unit of analysis is often applied in network and cluster studies [29] in which interaction is the object of study. What stands out is that there is little building in the approaches on the one hand, while on the other the choice of the unit of analysis is often not in line with the nature of the research questions raised.

Partly related to the unit of analysis issue is the question of how to delineate the system, i.e. setting the boundaries of the system? This is the second methodological issue discussed here. When the focus is on a product group or a set of related product groups, as is often the case within the context of National Innovation Systems or cluster approaches, the delineation seems not to be a large issue as standard industrial classifications are often used. When for example a technology/knowledge field is the unit of analysis, one also has to determine what falls inside and outside a particular knowledge field. This can, of course, not be done unless the researcher is familiar with the technological field and interacts frequently with technological specialists. One way of doing this would be to assess the distance between various technologies. Several attempts have been made to measure this closeness formally. However, these measures are often quite aggregated and provide little assistance when judging whether or not a specific technology is within the same knowledge field as another technology. Also the delineation of networks or clusters is not easy. Often researchers use the strength of formal and informal spillovers and their importance to innovation and productivity to determine boundaries. In any case, there is no reason to hide that delineation may often be somewhat arbitrary and partly based on informed guesses of the researcher. Moreover, in all cases it is important to use a consistent and explicit method to set the boundaries of a system of innovation.

A third methodological issue concerns the question of how to deal with the dynamic character of systems of innovations. A system of innovation is not static but evolves with alterations in the content of technologies, products as well as in the relationships among various technologies, products, institutions and actors. Although the System of Innovation approaches have their roots in evolutionary theory, it is somewhat surprising that there is little methodological attention for dynamic features of systems. This is why for example Lundvall et al. [22] argue that there is a need to 
find ways to capture the formation and evolution of innovation systems from their birth to their death at a macro level, and why Meeus and Oerlemans [23] ask for studies and methodologies to research the institutional dynamics underlying the creation of technical criteria at a micro level.

The fourth and last methodological issue that has to be addressed is the measurement of system performance. In a literature review of 158 studies on inter-organisational relations, interaction and networks, one of the research fields that can be considered as an antecedent of Systems of Innovation approaches, Oliver and Ebers [27] conclude that research has centred on the driving forces behind inter-organisational networking and interaction, rather than on the possible outcomes of these activities. Carlsson et al. [4] also point at the lack of attention for the measurement of performance of Systems of Innovation. They argue that the exact choice of performance measure is complicated and depends on the level of analysis applied as well as on the maturity of the system. Especially in the case of knowledge fields, it is quite difficult to determine economic performance since a specific knowledge field is rarely economically useful on its own since it needs complementary technologies.

\subsection{Systems of Innovation Management: policy issues}

From a policy perspective, Edquist and Hommen [7] state that the theoretical legacy of System of Innovation approaches, combining different but complementary theoretical views on interdependency and user-producer interaction, makes these approaches particularly useful for understanding demand side policy instruments, such as public technology procurement. Despite historical neglect of the demand side, especially in standard economic analyses of innovation, supply-side policies however remain important. Although most System of Innovation approaches stress the relevance of policy interventions by the state, one of its weaknesses is that it lacks a clear 'theory' about the role of the state [8]. Especially the (theoretical) mechanisms through which the state influences the innovation system, for example through innovation policies, are often lacking. He argues that such a theory is necessary because the state and its agencies are important determinants of innovation in any System of Innovation.

\section{DIRECTIONS OF FUTURE RESEARCH}

\subsection{Directions of future research: theory development}

\section{Increasing the degree of theoretical rigour and specificity}

To come to theory development, several scholars put forward suggestions. As Edquist [8] and Lundvall et al. [22] stated, there is a strong need for further conceptual and theoretical development and sharpening of the System of Innovation approach. To make the approach more 'theory-like'- for example include more specific statements about relations between variables - it is necessary to increase the degree of rigour and the specificity of the approach. A proper way to reach this goal is by actually using the approach in empirical and comparative research. This is because clear concepts and unambiguous statements are needed when empirical 
correspondences to theoretical constructs are sought. Hence, theoretically based empirical work is a proper way to straighten up the System of Innovation approach conceptually and empirically. This empirical work will function as a disciplining device in an ambition to develop the conceptual and theoretical framework.

A next question to answer is in which directions this theoretical and empirical work has to move. Edquist [8] suggests that researchers should focus on the determinants of innovation, activities in and functions of Systems of Innovation, since surprisingly enough little systematic and detailed research seems to have been done on these topics. In line with the above, Lundvall et al. [22] suggests that the evolutionary framework is a useful starting point, resulting from its emphasis on qualitative change and on the creation of diversity allowing for an integration of aspects of learning and innovation. This framework also allows the possibility of studying large-scale phenomena like the creation, transformation and passing away of innovation systems. Moreover, he contends that a key to further development of the Systems of Innovation approach is the understanding of processes of learning and competence building in the context of production and innovation systems. Therefore, more emphasis should be given to the subsystem related to human resource development. This especially includes the organisation of knowledge creation and learning within firms and in networks. According to him, a special focus must be on the part of business services that specialise in producing, collecting and selling knowledge.

\section{Unpacking institutional arguments}

Meeus and Oerlemans [23] contend that the theoretical challenge is to relate entities at various levels and to different but inter-conditioning processes. They refer to Freeman and Soete [9] who asserted this by their statement that a clear understanding of national systemic interactions requires an essential theoretical bridge between macro and micro aspects of innovation processes and technological change. They conceive System of Innovation research as typically multi-level research in which interactions between different variables (firm specific, sectoral/technological and macro-economic and institutional) are considered a key issue. Accordingly, given the embeddedness of the innovation process in a seamless web of social forces that enable and constrain the innovative behaviour of firms, this asks for very sophisticated research, both from a theoretical and a methodological point of view.

Meeus and Oerlemans formulate several research agendas, which are connected with the weaknesses of the approach they outlined before. First, there has to be developed an institutional approach that allows for a broader set of institutions than only the Science and Technology supporting institutions. Mostly, researchers in the field apply a narrow account of institutions relevant for innovative capacity and definitions are often diffuse.

A possible direction might be, they argue, the socio-cognitive approach developed by Garud and Rappa [12], which links the macro and micro level by specific processes. They analyse how reciprocal interactions between beliefs and evaluation routines in the behaviour of members of technological communities affect the form and function 
of a new technology. These interactions give rise to two processes. One is a process of inversion at the micro level of individual cognition wherein evaluation routines designed to judge specific artefacts begin to reinforce researchers' beliefs. The other is a process of institutionalisation at the macro level of shared cognition. For Garud and Rappa, institutionalisation is in this context the development of a common set of evaluation routines that can be applied to all technological paths.

Secondly, in order to deal with the often disregarded relationship between the systems approach, institutions and the role of agency, Meeus and Oerlemans propose to develop a behavioural approach that explains how innovative firm behaviour and institutions affect each other reciprocally. The mechanisms explaining the relations between institutional arrangements and firm behaviour have to be specified and extended. They propose a number of building blocks to fill the gap. Since System of Innovation approaches mostly focus on connectivity and capabilities, old exchange theory and modern network theory could be of importance here. Furthermore, the socalled legitimisation and reputation processes [30] which link firm behaviour to institutional contexts, and function as sources of attraction between actors are seldom taken into account in the Systems of Innovation literature. A way to deal with this issue is to study how institutional dynamics influence the creation of technical criteria, but also how beliefs, routines and artefacts in iterative evaluation processes add to the legitimacy of artefacts. The research may pertain to the way in which innovative performance of firms generates status orderings, and creates favourable reputations, and accordingly legitimises their behaviours.

To avoid the determinism and functionalism of the systems approach, institutional impacts on organisation behaviour could be qualified in terms of the room for strategic choices left to organisations. Scott [32] distinguishes several types of connections between institutional environments and organisational structures (including organisational and strategic behaviour): (1) The imposition of organisational structure; (2) the authorisation of organisational structure; (3) the inducement of organisational structure; and (4) the acquisition of organisational structure. These four processes connecting institutional environments to organisational structure clarify how the strength of institutional environments varies and diminishes the opportunities for strategic choice of individual organisations that are a part of this environment. Within this line of thought, comparative studies between Systems of Innovation in different countries with respect to the prevalence of these processes could lead to value new insights.

Furthermore, the institutional drag hypothesis predicts that institutions through their inertia and rigidity inhibit the dynamics of technological development [18]. Institutions are regarded as inflexible and institutional change is supposed to be lagging behind technological change. This creates mismatch problems, which often hamper the full realisation of the productive potential of new technologies. However, institutions also enable innovation, search and learning activities. Different ways of organising external activities (inter-organisational co-operation, co-makership, R\&D collaboration) are important representations of the utilisation of the social capital that is available in societies. In this line of thought possible research agendas could be: (1) an effort to specify the mechanisms explaining the constraining and enabling 
features of institutional set-ups of Systems of Innovation on the innovative performance of organisations, and (2) an effort to determine the extent to which certain types of Systems of Innovation support radical or incremental innovation, respectively.

\section{Addressing the problem of change and dynamics}

Finally, the problem of change of Systems of Innovations needs further analysis. Different issues have to be addressed. Lundvall et al. [22] contend that the last decades have been characterised by a transformation to what has been labelled as 'the learning economy'. In their view, this new context is more than anything else characterised by a speed up in the rate of change giving a stronger importance to learning processes for economic performance. To understand this process of transformation, it is useful to analyse and understand how specific Systems of Innovation respond to global trends and challenges, because some Systems may, for historical reasons, be better prepared to cope up with this new context than others.

Meeus and Oerlemans [23] propose to focus on changes of Systems of Innovation across countries. Which countries have a rapidly evolving System of Innovation? They refer to Galli and Teubal [11], who raise the issue of the modelling of transition of old closed Systems of Innovation with little interaction and sectoral support systems, to open ones with a lot of interaction between the building blocks, oriented toward knowledge demand and supported by a variety of interfacing units. They add to this the identification and specification of system aspects with which one can study input levels, utilisation of inputs, throughput mechanisms, feedback loops and the law of requisite variety and propose to focus on the question whether this transition is associated with patterns of specialisation or performance differences.

A third research line in which change and development is addressed is advocated by Lundvall et al. [22]. They argue that there is a need to broaden the analysis of (economic) change and development and to study how knowledge production and innovation is conditioned by and affects social and ecological sustainability. As pointed out by Freeman [10], the ecological challenge should be integrated in any strategy for economic development. An important question here is how to integrate intangible (e.g. intellectual) resources and less reproducible resources (e.g. natural and social capital) in the Systems of Innovation approach in a fruitful way and to study how (technological) innovation affects social and ecological sustainability.

\subsection{Directions of future research: methodological issues}

The theory development issues discussed in the previous section have a number of methodological implications, which are dealt with in this section. In line with the call for a higher degree of rigour and specificity and for more theory-based empirical research, disaggregation is crucial for progress with regard to identifying the determinants of innovation. Therefore, meso and micro level analysis is important [8]. By implication, this means that researchers have to focus especially on the collection of micro data that can help to validate and test these more sophisticated theoretical models. Such work would increase knowledge about determinants, 
functions and activities in systems, and this knowledge could then be a basis for further empirical generalisations to develop the rather descriptive Systems of Innovation framework into a more robust theory. Theory-based empirical research is not only helpful for achieving a higher degree of rigour and specificity, but also enables researchers to take a more cumulative research approach in which complementary competing innovation theories are combined in a fruitful way. Furthermore, there is need for more comparative research. One of the characteristics of the System of Innovation approaches is that technological innovation and change is conceptualised as an open-ended and path-dependent process where no optimal solutions can be identified. Technologies and innovations that are developed are only superior in a relative sense, not optimal in an absolute sense, and - contrary to standard economic theory - the system never reaches a state of equilibrium. Thus, understanding and explaining differences between Systems of Innovations should come more into focus. This means conducting comparisons between existing systems rather than between real systems and an ideal or optimal system. This comparative research strategy would add to attaining the higher degree of rigour and specificity that is desired. Such comparative analyses could also be helpful for the identification of deficiencies in the functioning of a system. Only with knowledge about such 'system failures', does it become possible to design specific innovation policies. To study the dynamics of Systems of Innovation longitudinal and historical research designs are needed. Although difficult to achieve, such designs will be helpful to understand the determinants and effects of change in Systems of Innovation. As was stated before, these research designs can be applied to different levels on analysis ranging from the study of the evolution of systems to the study of innovation and network dynamics at the micro level. Finally, the measurement of system performance that is the mapping of innovation systems should receive more attention. When interested in the performance of an innovation system, we may evaluate how each individual part of a system performs (e.g. the firms, the educational and research system), but an important challenge lies in the measurement of the performance of the total system. Carlsson et al. [4] suggest several performance indicators of the generation of knowledge (number of patents, number of engineers/scientists, mobility of professionals, number of technological fields as an indicator of diversity) as well as indicators of the diffusion (stage of development, regulatory acceptance, number of distributed licences) and use of knowledge (employment, turnover, growth). Indicators used in the evaluation of supply-chains could lead to a fruitful cross-fertilisation.

\subsection{Directions of future research: policy issues}

In the above, it was argued that one of the weaknesses of the System of Innovation approach is that it is still lacking the treatment of power aspects. The focus on interactive learning may lead to an underestimation of the conflicts over the revenues (e.g. income, sales, new knowledge) and power, which are also connected to the innovation process. Interactive learning and innovation immediately sounds like a purely positive sum game, in which everybody gains. One could label this as the cooperation and innovation bias of the Systems of Innovation approaches. In fact, there is little learning without forgetting. Skills and competencies are rejected and destroyed and many actors experience decreasing revenues and influence. Increasing 
rates of learning and innovation may lead not only to increasing productivity and yields but also to increasing polarisation in terms of the distribution of power between actors in a system of innovation. Aspects of power are also often neglected in discussions about innovation policy based on the System of Innovation approach. For example, an important mechanism behind the formulation and implementation of innovation policy is lobbying. Private firms, state agencies and other organisations often act with the objective of influencing innovation policies to get them designed and implemented in their own interest. Lobbying is often a conserving mechanism, since it requires that the lobbyists have an (economic) power position and it works to permanent status quo, for example with regard to the structure of production. Thus, to counteract the cooperation and innovation bias often present in Systems of Innovation approaches, there is a need to include theoretical notions about aspects of power and to study the effects of asymmetrical power relations between actors on processes of interactive learning, innovation and policy making. When it comes to supporting innovation processes through different kinds of policies, there is a growing consensus on the need to focus on long-term competence building in firms and in society as a whole [22]. At the same time, the prevailing institutional set-up and global competition tends to give predominance to short-term financial objectives in policy making. To study the effects of this paradox and to develop interventions that counter short-term views could be an interesting challenge. Another important potential of applying the innovation system concept and to pursue comparative studies of different systems is to get a critical understanding of the limits of specific (national) policy strategies. Policies aiming at promoting industrial development through innovation will often tend to follow specific trajectories and often they will be more successful in reinforcing the system where it is already strong. As a result, the danger of lock-ins is always present. To overcome lock-ins and the impact of vested interests in defining the policy agenda, the System of Innovation perspective and its use in comparative analysis could be helpful. Finally, the development of intervention options is a research challenge for the Systems of Innovation approach. Edquist and Hommen [7] contend that although systems approaches on innovation yield a more fruitful perspective on a demand-side orientation in innovation policies, this does not mean that the approach already has developed a systematic policy toolbox for different actors. On the contrary, at the moment there is a diverse set of complementary components (including lead user strategies, public technology procurement, market creation for innovative products) but not a structural and consistent policy framework. Therefore more work has to be done, especially if social and ecological sustainability issues also have to be taken into account in this policy framework [22].

\section{CONCLUSIONS AND DISCUSSION}

This paper evaluated the System of Innovation approach, which is adopted by South African government as its policy framework. More specifically, it answered the research question: What are the theoretical, methodological, and policy problems and challenges of the System of Innovation approach?

From this paper, the Systems of Innovation approach may be a fruitful framework for analysing innovation and design science and technology policies, since it takes the 
systemic features of 'modern' innovation processes in and between organisations into account. Nevertheless, the paper also showed that these approaches are to a certain extent still rather problematic. It was indicated that from a theoretical, as well as from a methodological and policy point of view many research efforts still have to be conducted to come to a scientific mature framework. Given the current state of affairs in Systems of Innovation approaches, it is our opinion that policy makers using this approach as their policy framework should be aware of the problems and pitfalls outlined in this paper. An example could illustrate our argument.

As was explained in the introduction of this paper, the South African government identified, as many countries did, a number of technology missions (e.g. biotechnology and information technology) that are regarded as key to promote economic and social development of the nation. Moreover, according to government, this portfolio of missions needs to be managed in a coherent and integrated way. From a 'pure' system of innovation approach, however, the identification of key technology and innovation areas and supporting those with governmental funding (e.g. Innovation Fund) is somewhat alien and assumes that (technological) innovation in sectors and countries can, to a certain extent, be planned, programmed and managed. The system of innovation approach argues quite the opposite. Since the approach is theoretically grounded in interactive learning and evolutionary approaches, it assumes that innovation is by definition a process with uncertain outcomes. Therefore, if it were possible to predict the production of innovations in certain technology areas or missions upfront, the system of innovation approach would conclude that no real innovation occurred.

Does this mean that a policy maker using the system of innovation approach as a framework has no tools at her or his disposal? No, not at all. For stimulating innovation, attention could be paid to those processes that stimulate unexpected outcomes and diversity regardless of the sector that generates these outcomes [26]. As Schumpeter [31] already argued, innovation is often the result of 'new combinations'. In modern economies, these new combinations often surface at intersections of complementary technologies or (sub)sectors [15]. As an implication this means that two processes are of vital importance to innovation in a country or sector: interaction and absorption. Interaction between actors in a system of innovation is important because it facilitates knowledge development (e.g. interactive learning and knowledge transfer and sharing), the coordination of resources (e.g. adapting innovations to a technical system) and the mobilisation of resources (e.g. access to knowledge sources). Interaction between actors in Systems of Innovation will be less or inefficient if the absorptive capacity of actors is insufficiently developed. Absorptive capacity refers to the ability of actors to recognise the value of new, external information, assimilate it, and apply it to commercial ends. In other words, if actors are not able to process the knowledge and information that is generated and transferred through interaction, the innovative productivity will be hampered.

Therefore, stimulating innovation and diversity on the basis of the system of innovation approach implies that policy measures could be put in place that support interaction processes and increase the absorptive capacity of organisations. An 
important policy instrument for supporting interaction processes is stimulating cooperation between, especially small and medium sized, firms. Knowledge intermediaries and brokers could play an important role here as well as initiatives that provide infrastructures for interaction (like e.g. science parks). Stimulating the development of absorptive capacity asks for policy instruments that increase (innovation and collaboration) competences. Human resource development and the development of competences in the field of relationship management (e.g. how to deal with relational risks in cooperation) could be relevant pillars of policy.

The examples discussed above show that a technology and innovation policy rooted in the System of Innovation approach basically tries to stimulate internal and external knowledge production and knowledge flows in an economy. Both processes could speed up economic growth and prosperity in a nation.

\section{REFERENCES}

[1] Anderson, P. and Tushman, M.L. 1990. Technological discontinuities and dominant designs - a cyclical model of technological change. Administrative Science Quarterly, 35(4), pp 604-633.

[2] Arrow, K.J. 1962. Economic welfare and the allocation of resources for invention. In: The Rate \& Direction of Inventive Activity, Princeton University Press.

[3] Carlsson, B. 1995. Technological systems and economic performance: the case of factory automation, Pinter.

[4] Carlsson, B., Jaconsson, S., et al. 2002. Innovation systems: analytical and methodological issues, Research Policy, 31, pp 233-245.

[5] DeBresson, C. and Amesse, F. 1991. Networks of innovators: A review and introduction to the issue, Research Policy, 20, pp 363-379.

[6] Demsetz, H. 1969. Information and efficiency: another viewpoint, Journal of Law \& Economics, 12, pp. 1-22.

[7] Edquist, C. and Hommen, M. 1999. Systems of Innovation: theory and policy for the demand side, Technology in Society, 21, pp 63-79.

[8] Edquist, C. 2001. The Systems of Innovation approach and innovation policy: An account of the state of the art, DRUID Conference 2001, Aalborg, Denmark.

[9] Freeman, C. and Soete, L. 1997a. The economics of industrial innovation, Pinter.

[10] Freeman, C. 1997b. Innovation systems: city-state, national, continental and sub-national, University of Sussex, SPRU.

[11] Galli, R. and Teubal, M. 1997. Paradigmatic shifts in national innovation systems. In: Systems of Innovation: technologies, institutions and organizations, C. Edquist (eds), Pinter Publishers, pp 343-370.

[12] Garud, R. and Rappa, M. A. 1994. A socio-cognitive model of technological evolution: the case of cochlear implants, Organization Science, 5, pp 344-362.

[13] Gelsing, L. 1992. Innovation and the development of industrial networks. In: National Systems of Innovation: Towards a theory of innovation and interactive learning, B.-A. Lundvall (eds), Pinter Publishers. 
[14] Geroski, P.A. 1990. Innovation, technological opportunity, and market structure, Oxford Economic Papers, 42(3), pp 586-602.

[15] Håkansson, H. 1989. Corporate technological behavior: Co-operation and networks, Routledge.

[16] Hippel, E. von 1988. The sources of innovation, Oxford University Press.

[17] Jadlow, J.M. 1981. New evidence on innovation and market structure, Managerial and Decision Economics, 2(2), pp 91-96.

[18] Johnson, B. 1992. Institutional learning. In: National Systems of Innovation. Towards a theory of innovation and interactive learning, B.-A. Lundvall (eds), Pinter Publishers, pp 23-44.

[19] Kline, S. J. and Rosenberg, N. 1987. An overview of innovation. In: The positive sum strategy, R. Landau and N. Rosenberg (eds), National Academy Press.

[20] Lundvall, B.-A. 1985. Product innovation and user-producer interaction, Aalborg University Press.

[21] Lundvall, B.-A. 1992. National Systems of Innovation: Towards a theory of innovation and interactive learning, Pinter Publishers.

[22] Lundvall, B.-A., Johnson, B. et al. 2002. National systems of production, innovation and competence building, Research Policy, 31, pp 213-231.

[23] Meeus, M. and Oerlemans, L.A.G. 2005. National Innovation Systems. In: Institutions and Innovation, F. van Waarden and S. Casper (eds), Edward Elgar, pp 40-53.

[24] Metcalfe, J. 1995. The economic foundations of technology policy: equilibrium and evolutionary perspectives. In: Handbook of economics of innovation and technological change, P. Stoneman (eds), Blackwell.

[25] Nelson, R.R. and Winter, S.G. 1982. An evolutionary theory of economic change,Belknap Press.

[26] Nooteboom, B. 2004. Innovatie: theorie en beleid, Tilburg University.

[27] Oliver, A.L. and Ebers, M. 1998. Networking network studies: an analysis of conceptual configurations in the study of inter-organizational relationships. Organisation Studies, 19, pp 549-583.

[28] Podolny, J.M. and Stuart, T.E. 1995. A role-based ecology of technological change, American Journal of Sociology, 100, pp 1224-1260.

[29] Porter, M.E. 1998. Competitive advantage: creating and sustaining superior performance, The Free Press.

[30] Rao, H. 1994. The social construction of reputation: certification contests, legitimation, and the survival of organizations in the American automobile industry: 1895-1912, Strategic Management Journal,15,pp 29-44.

[31] Schumpeter, J.A. 1983. The theory of economic development: an inquiry into profits, capital, credit, interest, and the business cycle, Transaction Books.

[32] Scott, W.R. 1991. Unpacking institutional arguments. In: The new institutionalism in organizational analysis, W. Powell and P. DiMaggio (eds), The University of Chicago Press, pp 164-183.

[33] Smith, K. 1995. Interactions in Knowledge Systems: Foundations, Policy Implications and Empirical Methods, STI Review, no. 16, OECD, pp. 69-102. 
[34] White Paper on Science and Technology. Preparing for the $21^{\text {st }}$ Century. 1996. Department of Arts, Culture, Science and Technology, The Government of South Africa.

[35] Williamson, O.E. 1985. The Economic Institutions of Capitalism. Firms, Markets and Relational Contracting. New York: The Free Press. 